\title{
Motor Engine Controlling Helmet
}

\author{
${ }^{1} \mathrm{~K}$ Radhika, ${ }^{2} \mathrm{P}$ Shivani Patel, ${ }^{3} \mathrm{G}$ Shivani, ${ }^{4} \mathrm{~K}$ Sanjay, ${ }^{5} \mathrm{~B}$ Geetavani, ${ }^{6} \mathrm{C}$ S L Vijaya Durga \\ ${ }^{1,5,6}$ Assistant Professor, Institute of Aeronautical Engineering, Dundigal, Hyderabad-43. \\ 1radhi.rk2007@gmail.com, ${ }^{5}$ geetavanics06@gmail.com, vijayadurga.csl@gmail.com \\ ${ }^{2,3,4}$ UG Student, Department of CSE, Institute of Aeronautical Engineering, Dundigal, Hyderabad-43.
}

\begin{abstract}
An accident is an unexpected action that takes place at a certain time and place with no obvious cause but with noticeable effects. Lack of care and neglect of safety measures on part of the rider are the major factors for accidents. Vehicle operators tend to violate the basic instructions given by the traffic guides in every state. The rising number of accidents involving motorcycles is an alarming issue. The objective of the system is to reduce the biker accidents by turning off the engine when there is no helmet to prevent accidents and make bikers journey safe. To make drivers ride safe we are adding few features to the helmet-like alcohol sensor which detects the person's alcohol percentage and prevents the bike from starting, vibration sensor to detect whether the biker wore his/her helmet. Most people tend to neglect the importance of the helmet and discard it. A statistical analysis of the same reflected the fact that a significant number of deaths could have been avoided, had there been a helmet. Most people tend to neglect the importance of the helmet and discard it. The Smart Helmet without human intervention detects whether the person is nonalcoholic breath while driving and wearing the helmet. This smart helmet collects, generates, and converts information on sensors. The collected information for helmet sensors is used to monitor the bike through gear motor. This study is integrating the alcohol and vibration sensor with the Arduino. Along with the controller we also have other components for indicating the violated conditions.
\end{abstract}

Key words: Accident avoidance, drunken driving, helmet, alcohol sensor, vibration sensor.

\section{INTRODUCTION}

An accident happens in a particular place and time with unexpected, unusual, and unintended external actions with no deliberate cause but which effects with some specific marks. These accidents can be of any kind, for example, the collision between animals and vehicles when traveling through roads, vehicles, and pedestrians while crossing, or vehicles colliding with a fixed object. In the Indian road system, the widening of the road is not a substitute solution to stay away from traffic in a city. Increasing records of road accidents most particularly two-wheeler accidents. [6] There is a chance of an instance of being injured or in few cases no longer alive as well. The most common types of injuries include:

Head injuries

- Fractures

- Knee injuries

- Swollen muscles

The smart system comprises of an alcohol sensor and a helmet sensing sensor/vibration sensor (or an LDR). The Sensor is utilized to recognize whether the motor biker wore the head protector (helmet). Liquor/Alcohol sensor helps to distinguish whether the biker is tanked or not, the yield is taken care of to the Arduino. These sensors are equipped in the helmet. If any of the circumstances are damaged the motor won't be crooked HIGH. An alcohol sensor is utilized for recognizing the liquor focus present in the driver's gasp. It gives a simple resistant yield dependent on the liquor focus. Arduino is an opensource tool that connects the physical devices, gets information from these sensors, and compares to the predefined values given by the system while developing to check whether are conditions are fulfilled or not. A buzzer associated with any of the pins of an Arduino which gets enabled when any of the conditions are violated. Our goals for this paper are to ensure rider safety through the means of introducing several features using the smart helmet. The paper can be broadly classified into two subparts, the Smart Helmet and the Processor circuit (which 
will be integrated into the bike). This paper discusses the design of high safety motorcycle helmets with the analysis of motorcycle helmet's function, material, ergonomics, and structure at affordable prices. the study is to design a framework that can amend the safety of motorcyclists, to introduce a Smart safety helmet intended for a safe two-wheeler ride, to provide a protective cap at an affordable price so that every rider can make use of it, to reduce the effect of accidents on people and their families, To ensure a safe and peaceful journey of the two-wheeler.

\section{LITERATURE REVIEW}

This paper titled "Alcohol Detection using Smart Helmet", mainly concentrates on detecting alcohol percentage of the rider which is one of the possible reasons for the two-wheeler accidents. The working principle of this helmet is that it uses MQ- 3 gas detector which is an alcohol sensor to detect alcohol levels from the riders' breathing. It can be positioned just under the face protect and on top of the other face protection so that the sensor can detect the alcohol from the breath. This study tends to program/set limits of the drink as $0.04 \mathrm{mg} / \mathrm{L}$ and adjusted the threshold accordingly. There is another sensor at the ear lobe which senses the flow of the blood. If both the criteria are met then the two control signals from the helmet unit are sent to the control unit of the vehicle and the vehicle stops immediately else works normally. [1] Though the theory of the paper looks simple and technically clear but somewhere lacks the practicality and this is developed for a single purpose.

According to the recent research paper in the year 2016 which is based on the technology of GSM and GPS for accident detection and reporting system, the author mainly developed this product to improve the safety of the riders. In this paper, there is a study and understanding of RF transmitter and RF receiver circuit concepts. It also uses buzzer for indication whenever the accident occurs. With the help of that indication, the accident spot is noted and the information is sent to the registered our supervisor's unceasing ideas helped me in this research and that made me write this thesis mobile number. But the main disadvantage of this paper is that it does not display the current status of the motor because they didn't use any display device. The cost of the helmet is also high as they use GSM and GPS trackers. [2]
A paper in 2015 named "Smart Helmet" focuses mainly on using helmet by the riders. According to a survey nowadays due to the busy schedule of people in the competitive world, the death trolls of motorbike accidents are increasing day by day. And most of these accidents are due to the absence of a helmet. [3] Traffic Police cannot monitor every vehicle on the roads of the city. That is why his primary concern is to make riders use the helmet compulsorily.

This author proposed the feature that the bike doesn't start unless the rider puts the helmet. So this module deals with the riders whether wearing the helmet or not in the first place to achieve the signals from the sensor (ultrasonic sensor). These signals are been sent to the next module for authentication purposes. They used Arduino in the paper which is an opensource tool for connecting devices. The major drawback of this paper is that it uses an ultrasonic sensor which is very expensive and microcontroller though used for many purposes but cannot cope up with the future needs and technologies.

Another research paper titled "Microcontroller based smart wear for driver safety", published in the year 2015 discusses the speed of the vehicle. In this application the sensors or the devices used in the paper tracks area that the bike is passing through and controls the speed limit on entering any cautionary areas like hospitals, schools, and places with heavy traffic. There is an LCD that shows various messages after wearing a helmet. [4]

The author mainly concentrated on the accidents due to the over speed of vehicles but as we know that the accidents are not just because of the speed limit nut also other parameters like alcohol consumption, not wearing a helmet, etc.

An author from SRM University proposed a "HiTech Smart Helmet System", his system comprises of an alcohol sensor and a helmet sensing sensor. The Sensor is used to detect whether the biker is using a helmet. An alcohol sensor is used to detect the drunkard state of the biker; the output is fetched to the Arduino. All of these sensors are arranged in a helmet. If one of the constraints is violated or not satisfied, the engine not turns ON. An alcohol sensor helps to detect the alcohol there in the driver's gasp. The sensor gives an output in the form of signals based on the alcohol concentration through analog pins. Arduino is the microcontroller unit, which controls all the functions of other blocks in this 
system. It reads data from the sensors as input and controls all the functions of the whole system by synchronizing these data. Arduino receives data from these sensors through analog pins and it gives a digital data corresponding to the output of sensors to the encoder only if all the conditions get satisfied. A buzzer connected to a pin of the Arduino which gets enabled when any of the conditions are violated. [5]

\section{PROPOSED SYSTEM}

In this study, an alcohol sensor is used which helps in detecting the alcohol blood level percentage. This low-cost and easy to develop paper detects the presence of liquor from the riders breath who is drunk and driving the motorbike. After sensing the alcohol percent, a signal will be sent to the Arduino and an alarm/buzzer is enabled.

The system uses a vibration sensor or an LDR to detect whether the biker wore the helmet or not. The circuit is arranged in such a way that the bike engine won't start until the helmet is worn. This is done by using a vibration sensor which will detect the vibrations when the head of the biker touches the sensor. If we use an LDR as it is very sensitive and can detect even smaller light, this also helps in detecting the helmet.

This paper is to ensure the safety of the motorcyclist by using the latest technology and add up a few features to create a new system to satisfy the public needs where the existing products failed to satisfy. To ensure the protection and healthiness of every human being motorcyclist by design a harmless product that is easy to use and is also affordable. Reduce the number of accidents occurring everyday by solving the major issues

\subsection{Architecture}

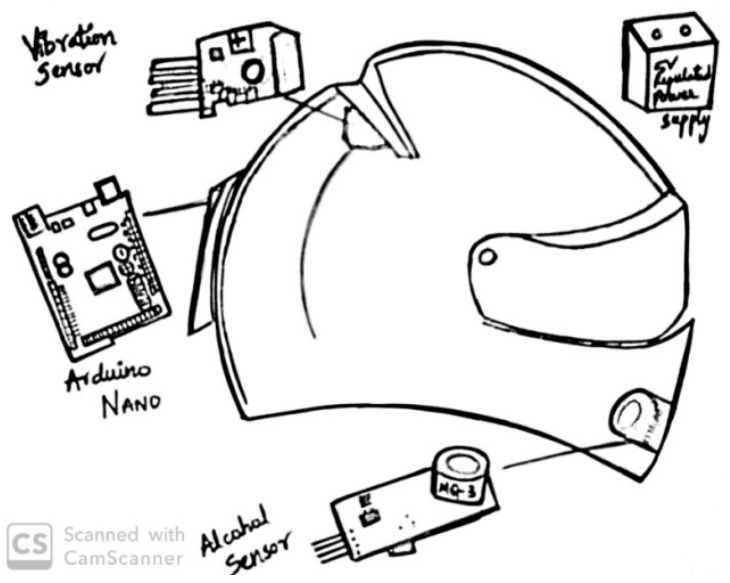

Figure 1: Architecture of the system
In the figure 1, we have seen a couple of sensors and a battery and also a buzzer which indicates if the conditions are not fulfilled. And to connect all these devices to gather we have an "Arduino Nano board" which connects devices, receives signals from the sensors, and generates output accordingly. We also have a $5 \mathrm{v}$ battery for the power supply which helps the Arduino and other devices to run as energy is one important thing to run any device. We first installed the code into the Arduino board with a few variables and conditions to make the system work. To the Arduino, we have many pins to connect to the " $n$ " number of devices.

\subsection{Block Diagram}

From the figure 2, we can see a controller which is an Arduino Nano board to which we provide a power supply of $5 \mathrm{v}$. With this $5 \mathrm{v}$ battery, we run the system for the prototype purpose but for this system to run on a motorbike we need a battery that can provide more power which can control the bike engine. As an input to this board, we have an alcohol sensor and vibration Sensor/LDR to provide information to the board and the output will be a buzzer when at least one of the conditions fails to execute. As a result of these signals from the sensors, we control the engine of the bike using a power starter connection and a battery attached to it. If an LDR is used in the paper then we have to use a resistor that resists the power fluctuations and allows the LDR to work properly without any external disturbances. As this resistor is very sensitive to detect even a small frequency light we have to make sure that there is no issue from the battery side

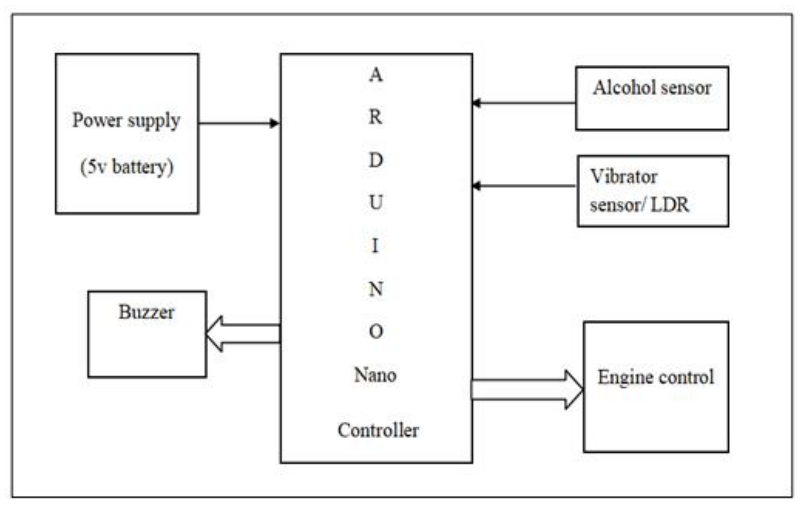

Figure 2: Block Diagram of the system 


\subsection{Software model}

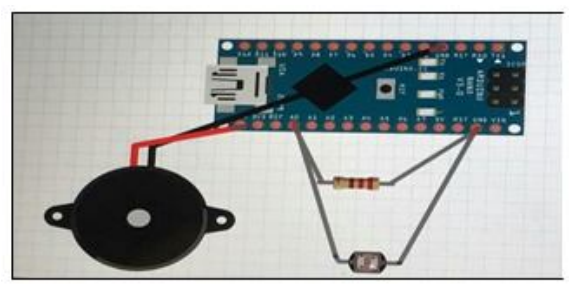

Figure 3: Design of components

\section{Flow chart representation}

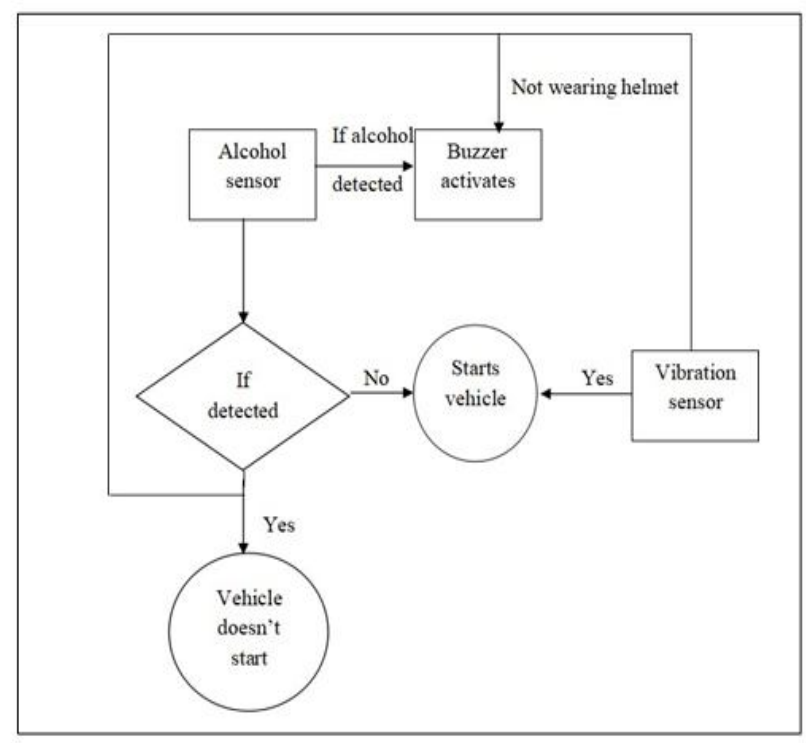

Figure 4: Flow chart representation of the system

\section{SYSTEM FUNCTIONALITY}

The principle on which this system works is that the alcohol sensor or the liquor sensor senses the alcohol percentage of the motorcyclist through his breath. This signal after sensing is given to the Arduino Nano controller unit. When there is zero alcohol content in the breath, there is nothing to send to the output device to enable and no signals given to disable the engine. In our paper, the 5-volt power supply is used to run the controller. The power supply is given as an input to the Arduino nano controller unit. From this controller we have an output pin; they are connected to the buzzer unit. The alcohol levels are predefined in the program from a particular limit to a particular limit. The second most important component is the vibration sensor. As we all know the purpose of the vibration sensor, here we are using it to detect the helmet wearing. We have seen many applications using a vibration sensor in home automation, smart cars, smart mobiles, etc.; we are using it for smart helmets now. As soon the biker wears the helmet there will be a vibration in the helmet due to sudden movement of the helmet and that movement is caught by the sensor. This vibration sensed by the sensor can be sent to the Arduino controller for the internal process. If the signals are high then the helmet is used else if the signals are low automatically a buzzer enables to indicate that the conditions mentioned are not satisfied. As a result of this output the engine doesn't start until the sensor senses positively (1).

A smart helmet for riders is developed with the sensors which are purely safe and give accurate results. We are here using Arduino nano which is small in size and fits correctly in the small space of the helmet without disturbing the components of the helmet. All the components used in this paper are nano even the breadboard. We wanted the device to look clean and clear without giving any heavy impression to the rider when he/she wants to use it. The buzzer in the system can be replaced with an LCD if wanted and can also use LED lights to indicate the violation of conditions by the rider.

\section{RESULTS}

Nowadays, most cases of accidents are seen by motorbikes. The severity and consequences of these accidents are increasing due to the absence of a protective cap or by drunk and driving. In our paper, we've designed an electronic smart helmet system that competently checks the wearing of a helmet and drunken driving. By using this technique a secure two wheeler drive is feasible which might reduce the top injuries during accidents caused by the nonexistence of helmet and as well decrease the accident rate. The sensors used are vibration sensor and alcohol sensor where the first one helps in detecting the helmet and the second one detects the alcohol content in the blood from the riders' breath. The signals sensed from the sensors are synchronized within the device and sent to the Arduino Nano controller board.

\subsection{Test case 1}

As mentioned in table 1, the usage of an alcohol sensor is for detecting the liquor percent and stops the engine to start if the biker is drunk. 
Table 1: Level of drunkenness of the sensor

\begin{tabular}{|c|c|c|c|}
\hline Input & \multicolumn{3}{|c|}{$\begin{array}{c}\text { Out } \\
\text { put }\end{array}$} \\
\hline $\begin{array}{c}\text { Level of } \\
\text { drunkenness }\end{array}$ & Buzzer & Engine & LCD \\
\hline $\begin{array}{c}\text { Below } \\
\text { 40ppm }\end{array}$ & Disabled & Enabled isplays \\
"Not drunk" & & \\
\hline $\begin{array}{c}\text { Above or } \\
\text { equal to } \\
440 p p m\end{array}$ & Enabled & Disabled Displays \\
\hline & & & "Drunk" \\
\hline E [e: & & \\
\hline
\end{tabular}

Figure 5: LCD screen indicating that the biker is drunk

\subsection{Test case 2}

Detecting the frequency of light from the helmet In this test case, we mainly focus on helmet detection. The code is given with some values as mentioned in the below table and the component works according to the values given to the device.

Table 2: Level of Frequency of the LDR

\begin{tabular}{|c|c|c|c|}
\hline Input & \multicolumn{2}{|c|}{ Output } \\
\hline $\begin{array}{c}\text { Level of } \\
\text { frequency }\end{array}$ & Buzzer & Engine & LCD \\
\hline $\begin{array}{c}\text { Below } \\
140 p t s\end{array}$ & Disabled & $\begin{array}{l}\text { Enable } \\
\mathrm{d}\end{array}$ & $\begin{array}{c}\text { Displays } \\
\text { "Helmet } \\
\text { wore" }\end{array}$ \\
\hline $\begin{array}{c}\text { Above or } \\
\text { equal to } \\
140 p t s\end{array}$ & Enabled & $\begin{array}{l}\text { Disable } \\
\mathrm{d}\end{array}$ & $\begin{array}{c}\text { Displays } \\
\text { "No } \\
\text { helmet" }\end{array}$ \\
\hline
\end{tabular}

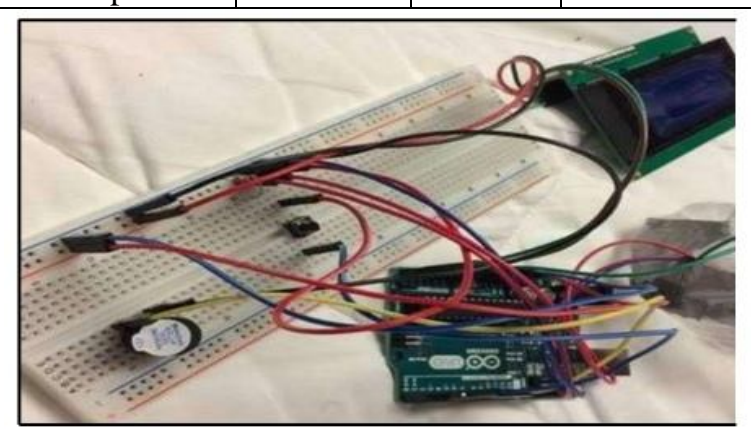

Figure 6: LCD screen detecting the pressure of the biker

\section{SUMMARY}

As per the research, it is very important to bring certain data which seeks everyone's attention. I.e., there is at least one death being reported every four minutes in India. In a recent survey WHO has identified 70 percent of injuries and 40 percent of deaths would be reduced if the rider wears a helmet. To avoid such cases Vehicle operators should follow the instructions given by the traffic authorities. As the affordable prices in addition to the availability of vehicles in different styles in the marketplace, $70 \%$ of the public favor motorbikes to purchase. Therefore their safety becomes a foremost concern. As a result, it is essential and also important to implement a system that cannot be bypassed by the riders to follow the basic rules of utilizing helmets properly and to keep away from drunk and driving.

This study made programmed a system that checks the status before turning the engine of the bike. Arduino which controls all the elements of different squares right now. It reads information and controls all the components of the entire system using the information given by sensors. These are the features added to this paper to ensure bikers' safety and our major concern is their safe journey.

\section{7 .CONCLUSIONS}

This system is extremely helpful for the security purpose of the user. The user has got to wear a helmet to ride two-wheeler vehicles and hence traffic rules will follow with this. This technique is under the control i.e. budget-friendly vehicles with all the safety measures. Easy functioning to implement this technique and provides far better security to the biker. The Smart Helmet is just user friendly with its new adaptable features.

The scope of this paper relies on the safety of the motorbike rider. Most of the motorcycle riders in recent days seem to be less afraid about their protection while riding, with Smart Helmet safety rates, is often increased and the chance of road accidents is often reduced. The accident rates for motorcyclists are increasing day by day everywhere on the planet. Smart Helmet for Motorcyclists using vibration sensor and Alcohol sensor is inspiring safety features for motorcyclists. This system analyzes or detects the existence of alcohol in the gasp is fairly a fast analysis as a contrast to other 
K Radhika et al., International Journal of Advanced Trends in Computer Science and Engineering, 9(1.5), 2020,321 - 326

techniques. The sensors are lesser in size, not so large, hence frequently carried.

The paper is sustaining this technology because it is independent within it and thus frequently used as a security system for any vehicle and, the person driving it is preventing the accidents to occur. This system can be added with a feature that can track easily with location when the bike is stolen or when the biker met with an accident. It can also be used to receive calls while driving through wireless Bluetooth Speakers. Instead of working directly with the gear motor, we can control the power starter of the bike as vehicles nowadays contain self- starter which is easier.

\section{REFERENCES}

1. Sudharsana Vijayan and Vineed T. Govind and Merin Mathews and S. Koonath Surendran, "ALCOHOL DETECTION USING SMART HELMET SYSTEM", 2014.

2. Lakshmi Devi, Bindushree, Deekshita .N, Jeevan, Likhith, "Helmet using GSM and GPS technology for accident detection and reporting system"-May 2016, INTERNATIONAL JOURNAL ON RECENT AND INNOVATION TRENDS IN COMPUTING AND COMMUNICATION, (Volume-4, Issue-5) EISSN: 2321-8169, May-2016

3. Saravana Kumar, Anjana .B, Litto Thomas, Rahul .K, "Smart Helmet"-March 2016, INTERNATIONAL JOURNAL OF SCIENCE, ENGINEERING AND TECHNOLOGY RESEARCH, (Volume-5, Issue-3) March-2016

4. Abhinav Anand, Kumar Harsh, Kushal Kumar, Sourav "Microcontroller based smart wear for driver safety", Department of Instrumentation Technology ijret.org/volumes/2015v04/i05/IJRET20150405 009.pdf - 2015.

5. Sanjeev Uppal, "Hi-Tech Smart Helmet System", Department of Electrical and Electronics Engineering International Journal Of Engineering Research \& Management Technology ISSN: 2348-4039, volume 3 Issue 4, July- 2016.

6. Article from "The Hindu" [online] 2011 Feb. 10 http://www.hindu.com/2011/02/10/stories/ 1063740500.html
7. Article from "India Today" [online] https://www.indiatoday.in/diu/story/two-

wheeler- death-road-accidents-helmets-statesindia-1602794- 2019-09-24

8. Alcohol sensor and Automatic control system for bike," Volume 2, Issue ICRAET12, ISSN Online: 2277-2677, May-2012

9. Nissan to drink-drive-proof its vehicles, September2006,http://www.nissanglobal.com/EN/NEWS/ 200 7/_STORY/070723-01

10. Mohamed N, Batcha W, Abdullah N K, Yusuf M F, Rahim S, Mahmood M S, "Alcohol and drug use among fatally injured drivers in the urban area of Kuala Lumpur" (No. MRR 02/2012)," 2012

11. Honglie Leng, Yingzi Lin, "Design \& experimental study of CNT sensor for measuring alcohol content with short response delay," IEEE Sensor Journal, PP 1091-1097, 2010

12. Jiangpeng Dai, Jin Teng, Xiaole Bai, Zhaohui Shen, "Mobile phone-based drunk driving detection pervasive computing technologies for healthcare," 2010, 4th international IEEE conference, PP 1-8, March-2010 